\title{
Inhibition of Food Intake in Obese Subjects by Peptide $\mathrm{YY}_{3-36}$
}

\author{
Rachel L. Batterham, M.B., B.S., Mark A. Cohen, M.B., Ch.B., \\ Sandra M. Ellis, B.Sc., Carel W. Le Roux, M.B., Ch.B., \\ Dominic J. Withers, M.B., B.S., Ph.D., Gary S. Frost, Ph.D., \\ Mohammad A. Ghatei, Ph.D., and Stephen R. Bloom, M.D., D.Sc.
}

\section{ABSTRACT}

\section{BACKGROUN D}

The gut hormone fragment peptide $\mathrm{YY}_{3-36}(\mathrm{PYY})$ reduces appetite and food intake when infused into subjects of normal weight. In common with the adipocyte hormone leptin, PYY reduces food intake by modulating appetite circuits in the hypothalamus. However, in obesity there is a marked resistance to the action of leptin, which greatly limits its therapeutic effectiveness. We investigated whether obese subjects were also resistant to the anorectic effects of PYY.

\section{METHODS}

We compared the effects of PYY infusion on appetite and food intake in 12 obese and 12 lean subjects in a double-blind, placebo-controlled, crossover study. The plasma levels of PYY, ghrelin, leptin, and insulin were also determined.

RESULTS

Caloric intake during a buffet lunch offered two hours after the infusion of PYY was decreased by 30 percent in the obese subjects $(\mathrm{P}<0.001)$ and 31 percent in the lean subjects $(\mathrm{P}<0.001)$. PYY infusion also caused a significant decrease in the cumulative 24-hour caloric intake in both obese and lean subjects. PYY infusion reduced plasma levels of the appetite-stimulatory hormone ghrelin. Endogenous fasting and postprandial levels of PYY were significantly lower in obese subjects (the mean [ \pm SE] fasting PYY levels were $10.2 \pm 0.7 \mathrm{pmol}$ per liter in the obese group and $16.9 \pm 0.8 \mathrm{pmol}$ per liter in the lean group, $\mathrm{P}<0.001)$. Furthermore, the fasting PYY levels correlated negatively with the body-mass index $(r=-0.84, \mathrm{P}<0.001)$.

\section{CONCLUSIONS}

We found that obese subjects were not resistant to the anorectic effects of PYY. Endogenous PYY levels were low in the obese subjects, suggesting that PYY deficiency may contribute to the pathogenesis of obesity.
From the Department of Metabolic Medicine, Imperial College Faculty of Medicine at Hammersmith Campus, Du Cane Rd., London W12 0NN, United Kingdom.

N Engl J Med 2003;349:941-8. Copyright $(2003$ Massachusetts Medical Society. 


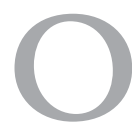

BESITY AND ITS ASSOCIATED PATHOlogic features are major causes of illness and death worldwide. In the United States, obesity accounts for 280,000 deaths annually, and at current rates of increase it will supplant smoking as the primary cause of preventable death. ${ }^{1}$ However, despite the recognition that even moderate weight loss confers significant health benefits, ${ }^{2}$ to date there have been few effective treatments for obesity, although surgery has been shown to be of use in selected patients. ${ }^{3}$

We recently showed that infusions of the gut hormone fragment peptide $\mathrm{YY}_{3-36}$ (PYY) that produced typical naturally occurring postprandial levels reduced 24-hour food intake in human subjects of normal weight. ${ }^{4}$ Furthermore, long-term administration of PYY to rodents decreased weight gain. These observations suggest that PYY may be a treatment for obesity. Given, however, that the majority of obese subjects are resistant to the effects of the adipocyte hormone leptin, limiting its effectiveness as an antiobesity treatment, ${ }^{5,6}$ we undertook to compare the effects of PYY infusion on appetite and food intake in obese and lean subjects.

\section{METHODS}

\section{STUDY SUBJECTS}

Healthy obese and lean subjects were recruited by advertising in local newspapers and on the Hammersmith Hospital campus in London. The mean ( \pm SE) body-mass index (the weight in kilograms divided by the square of the height in meters) was $33.0 \pm 0.9$ in the obese group and $20.5 \pm 0.1$ in the lean group. The inclusion criteria were a body-mass index of 27 to 40 for the obese group and 17 to 23 for the lean group. All subjects were between the ages of 18 and 50 years (mean, 29.0 \pm 2.4 for the obese group and $27.3 \pm 0.4$ for the lean group) and had had a stable body weight for at least three months. The criteria for exclusion were smoking, substance abuse, pregnancy, use of medications (except for oral contraceptives), medical or psychiatric illness, and any abnormalities detected on physical examination, electrocardiography, or screening blood tests (measurement of complete blood count, electrolytes, fasting glucose, and liver function).

Twelve subjects (six men and six women) were recruited for each group. The subjects gave written informed consent for the study, and approval was obtained from the Hammersmith Hospital research ethics committee. The study was carried out in ac- cordance with the principles of the Declaration of Helsinki. The subjects were screened by a dietitian who assessed their eating behavior with the Dutch Eating Behavior Questionnaire ${ }^{7}$ and the Eating Attitudes Test questionnaire. ${ }^{8}$ They also completed a three-day diet diary to permit us to assess their usual eating habits before acceptance into the study. Food preferences were assessed at screening with a nine-point hedonic scale to ensure that the food offered at the buffet lunch was acceptable.

\section{STUDY PROTOCOL}

The study was performed in a randomized, doubleblind, placebo-controlled, crossover manner, with each subject studied on two occasions one week apart. The subjects' food intake for the 48 hours before each study day was standardized, and during this period they completed food diaries to confirm compliance. In addition, they consumed an identical meal between 7 p.m. and 8 p.m. on the night before each study. The subjects refrained from alcohol and strenuous exercise for the 24 hours before and after each study day. They fasted and drank only water from 8 p.m. the night before the study. They arrived at 8:30 a.m. on each study day. Cannulas were inserted into veins in both forearms, one for the collection of blood and the other for the infusion of PYY or saline. After venous cannulation, the subjects relaxed for 30 minutes before the start of the study protocol. All time cues were removed from the study room, so that the subjects were unaware of the time. Throughout the study, the subjects were encouraged to relax by reading or watching videos.

Blood was collected every 30 minutes throughout the study into heparin-coated tubes (LIP) containing 5000 kallikrein inhibitor units $(0.2 \mathrm{ml})$ of aprotonin (Bayer). Plasma was separated immediately by centrifugation at $4^{\circ} \mathrm{C}$ and then stored at $-70^{\circ} \mathrm{C}$ until it was analyzed. Basal samples were taken 30 minutes before and at the beginning of the infusion. The subjects received a 90-minute infusion of either saline or PYY (total dose, $2 \mathrm{nmol}$ per square meter of body-surface area). Two hours after the termination of the infusion, the subjects were offered a buffet lunch with food in such excess that all appetites could be satisfied. The amounts of food and water were quantified preprandially and postprandially, and the caloric intake was calculated. Appetite ratings were made on 100-mm visual-analogue scales (higher values indicate greater appetite), with the text expressing the most positive and the most negative ratings anchored at each end. ${ }^{9}$ Visual-analogue 
scores were used to assess hunger, nausea, and meal palatability. The subjects remained in the study room for six hours after the beginning of the infusion. They completed a food diary until 1 p.m. the following day to allow continued assessment of food intake. The food diaries were analyzed by a dietitian who was unaware of study assignments, and energy intake was calculated with the aid of Dietplan (Forestfield Software).

PYY

PYY was obtained from Bachem. The limulus amoebocyte lysate assay test for pyrogen was negative, and the peptide was sterile on culture. PYY was dissolved in 0.9 percent saline (Bayer) containing Haemaccel (Beacon) (5 percent by volume) to reduce adsorption to the syringe and tubing.

\section{HORMONE ASSAYS}

All samples were assayed in duplicate and in one assay to eliminate the effects of interassay variation. PYY-like immunoreactivity was measured with a specific and sensitive radioimmunoassay, as previously described.10-12 The assay measured both the hormone fragment (peptide hormone $\mathrm{YY}_{3-36}$ ) and the full-length hormone (peptide hormone $\mathrm{YY}_{1-36}$ ); both are biologically active. The antiserum (Y21) was produced in a rabbit against synthetic porcine PYY (Bachem) coupled to bovine serum albumin by glutaraldehyde and used at a final dilution of 1:50,000. This antibody cross-reacts fully with the biologically active circulating forms of human PYY, but not with pancreatic polypeptide, neuropeptide Y, or other known gastrointestinal hormones.

Iodine-125-labeled PYY was prepared by the iodogen method and purified by high-pressure liquid chromatography. The specific activity of the iodine125-labeled PYY was $54 \mathrm{~Bq}$ per femtomole. The assay was performed in a total volume of $700 \mu \mathrm{l}$ of $0.06 \mathrm{M}$ phosphate buffer, $\mathrm{pH} 7.3$, containing 0.3 percent bovine serum albumin. The sample was incubated for three days at $4^{\circ} \mathrm{C}$ before the separation of free and antibody-bound label by sheep antirabbit antibody. Two hundred microliters of unextracted plasma was assayed. Two hundred microliters of PYY-free, charcoal-stripped plasma was added to standards and other reference tubes to negate any effects of nonspecific assay interference. The assay detected changes of 2 pmol per liter, with an intraassay coefficient of variation of 5.8 percent.

Plasma pancreatic polypeptide, insulin, and glucagon-like peptide 1 (GLP-1) were measured in du- plicate by established in-house radioimmunoassays The pancreatic polypeptide assay detected changes of 3 pmol per liter, with an intraassay coefficient of variation of 5.4 percent. ${ }^{13}$ The GLP-1 assay detected changes of 7.5 pmol per liter, with an intraassay coefficient of variation of 6.1 percent. ${ }^{14}$ The insulin assay detected changes of 6.2 pmol per liter, with an intraassay coefficient of variation of 5.4 percent. Plasma ghrelin was measured in duplicate with a Phoenix Pharmaceutical assay kit, and plasma leptin was measured in duplicate with a commercially available assay (Linco Research).

\section{STATISTICAL ANALYSIS}

Caloric intake and plasma hormone levels are expressed as means $\pm S E$. The integrated area under the curve was calculated with use of the trapezoid rule. Caloric intake and visual-analogue scores within groups were compared by the Wilcoxon signedrank, matched-pairs test. Areas under the curve and plasma hormone levels in the lean and obese groups were compared by Wilcoxon rank-sum analysis.

\section{RESULTS}

\section{EFFECT OF INFUSION OF PYY ON APPETITE \\ AND FOOD INTAKE}

PYY infusion reduced the caloric intake of all subjects at the buffet lunch, as compared with their intake after the infusion of saline (Fig. 1A and 1B). In the obese subjects, PYY caused a $29.9 \pm 4.4$ percent reduction $(\mathrm{P}<0.001)$ (Fig. 1C), and a similar decrease of $31.1 \pm 4.5$ percent was observed in the lean subjects $(\mathrm{P}<0.001)$ (Fig. 1D). There was no change in the proportion of calories obtained from carbohydrate, protein, or fat. Furthermore, analysis of the food diaries showed a significant inhibition of food intake in the 12-hour postinfusion period in both the obese and the lean subjects. In the obese group, on the day when the saline infusion was given, subjects consumed $2456.0 \pm 256.1 \mathrm{kcal}$, and on the day when the PYY infusion was given, they consumed $1810.3 \pm 142.6 \mathrm{kcal}$ - a reduction of $26.3 \pm 6.8$ percent. In the lean group, on the day when the saline infusion was given, subjects consumed 2312.2士 $167.7 \mathrm{kcal}$, and on the day when the PYY infusion was given, they consumed $1533.0 \pm 140.0 \mathrm{kcal}$ - a reduction of $33.7 \pm 5.6$ percent.

However, food intake during the period from 12 to 24 hours after infusion was unaffected by PYY in either group. In the obese group, on the day when

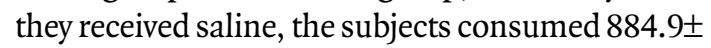




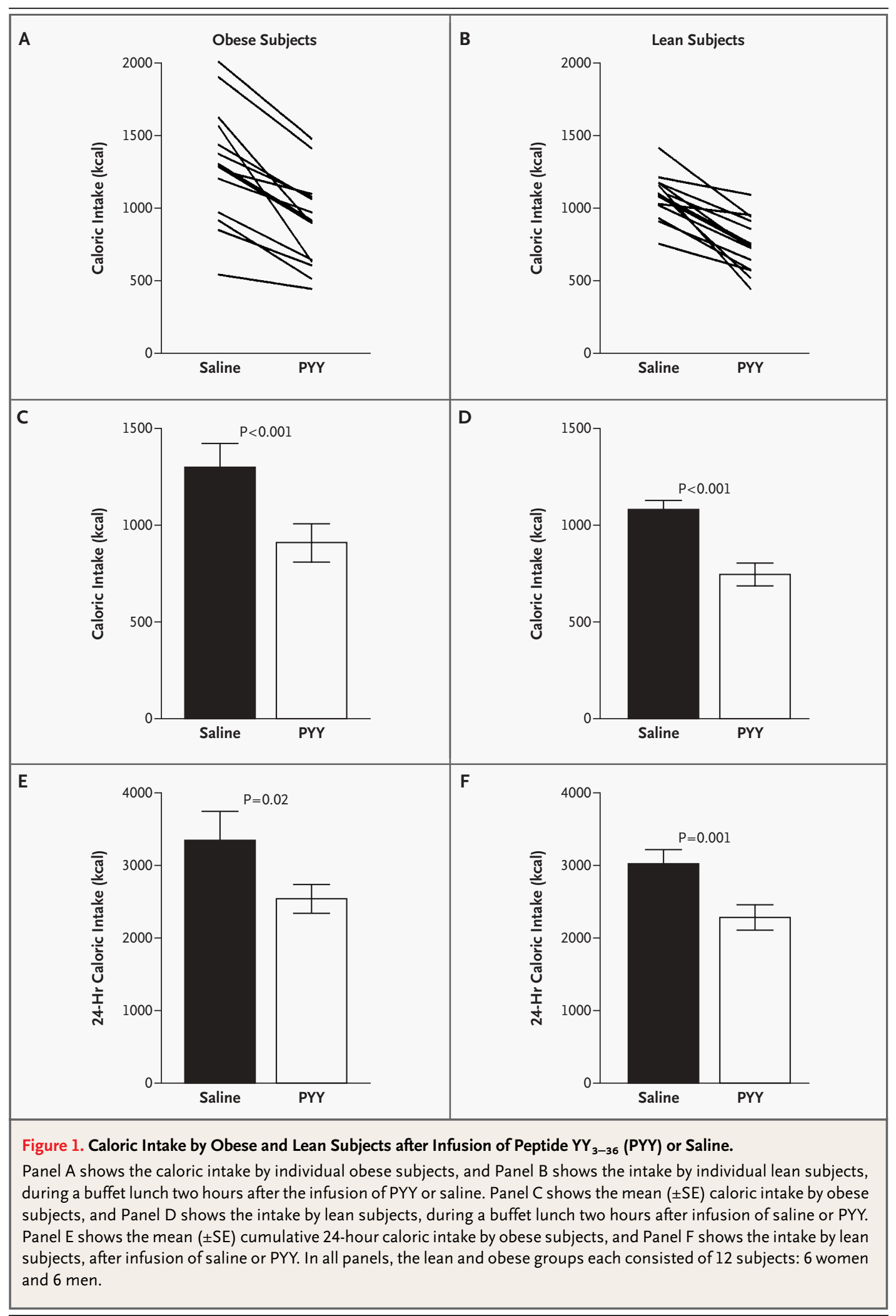


$170.4 \mathrm{kcal}$, and on the day when they received PYY, they consumed $723.7 \pm 118.6 \mathrm{kcal}$. In the lean group, on the day when they received saline, the subjects consumed $706.5 \pm 84.9 \mathrm{kcal}$, and on the day when they received PYY, they consumed $712.2 \pm 84.9 \mathrm{kcal}$. Overall, PYY significantly reduced 24-hour caloric intake (Fig. 1E and 1F) in both the obese and the lean groups. The reduction was $16.5 \pm 6.6$ percent in the obese group $(\mathrm{P}=0.02)$ and $23.5 \pm 5.8$ percent in the lean group ( $\mathrm{P}=0.001)$. PYY infusion reduced hunger, as assessed by visual-analogue scores (Fig. 2 ), but there was no effect on the palatability of the meal or feelings of nausea (data not shown). The subjects reported no other side effects during or after the PYY infusion.

\section{PLASMA LEVELS OF PYy}

PYY infusion produced similar plasma PYY profiles in the obese and lean groups. The peak PYY level was $57.1 \pm 3.8$ pmol per liter in the obese group and $53.7 \pm 3.5 \mathrm{pmol}$ per liter in the lean group.

Plasma PYY levels were measured in subjects receiving saline to make possible the assessment of fasting and postprandial levels (Fig. 3). The fasting PYY levels were significantly lower in obese than in lean subjects. The base-line PYY levels at the beginning of the infusion were $10.2 \pm 0.7 \mathrm{pmol}$ per liter in the obese group and 16.9 $\pm 0.8 \mathrm{pmol}$ per liter in the lean group $(\mathrm{P}<0.001)$. Furthermore, the area under the curve for PYY during the fasting period (from the beginning of the infusion until 210 minutes later) was significantly lower in the obese group than in the lean group: $558.6 \pm 43.0$ vs. $929.8 \pm 47.6 \mathrm{pmol}$ per hour per liter $(\mathrm{P}<0.001)$. The fasting PYY levels were negatively correlated with body-mass in$\operatorname{dex}(r=-0.84, \mathrm{P}<0.001)$ (Fig. 4).

The postprandial PYY levels increased in both lean and obese subjects. However, even though they consumed more calories at the buffet lunch, the obese subjects showed a diminished postprandial PYY response as compared with that in the lean subjects. The peak PYY value was $14.4 \pm 1.2$ pmol per liter in the obese group and $23.5 \pm 0.9 \mathrm{pmol}$ per liter in the lean group. In addition, the postprandial area under the curve for PYY (from 210 to 360 minutes after the beginning of the infusion) was significantly less in obese subjects than in lean subjects (562.0 \pm 44.6 vs. $841.4 \pm 34.9 \mathrm{pmol}$ per hour per liter, $\mathrm{P}<0.001)$.

PLASMA LEVELS OF GHRELIN

In the lean group, the levels of the appetite-stimulating hormone ghrelin increased throughout the

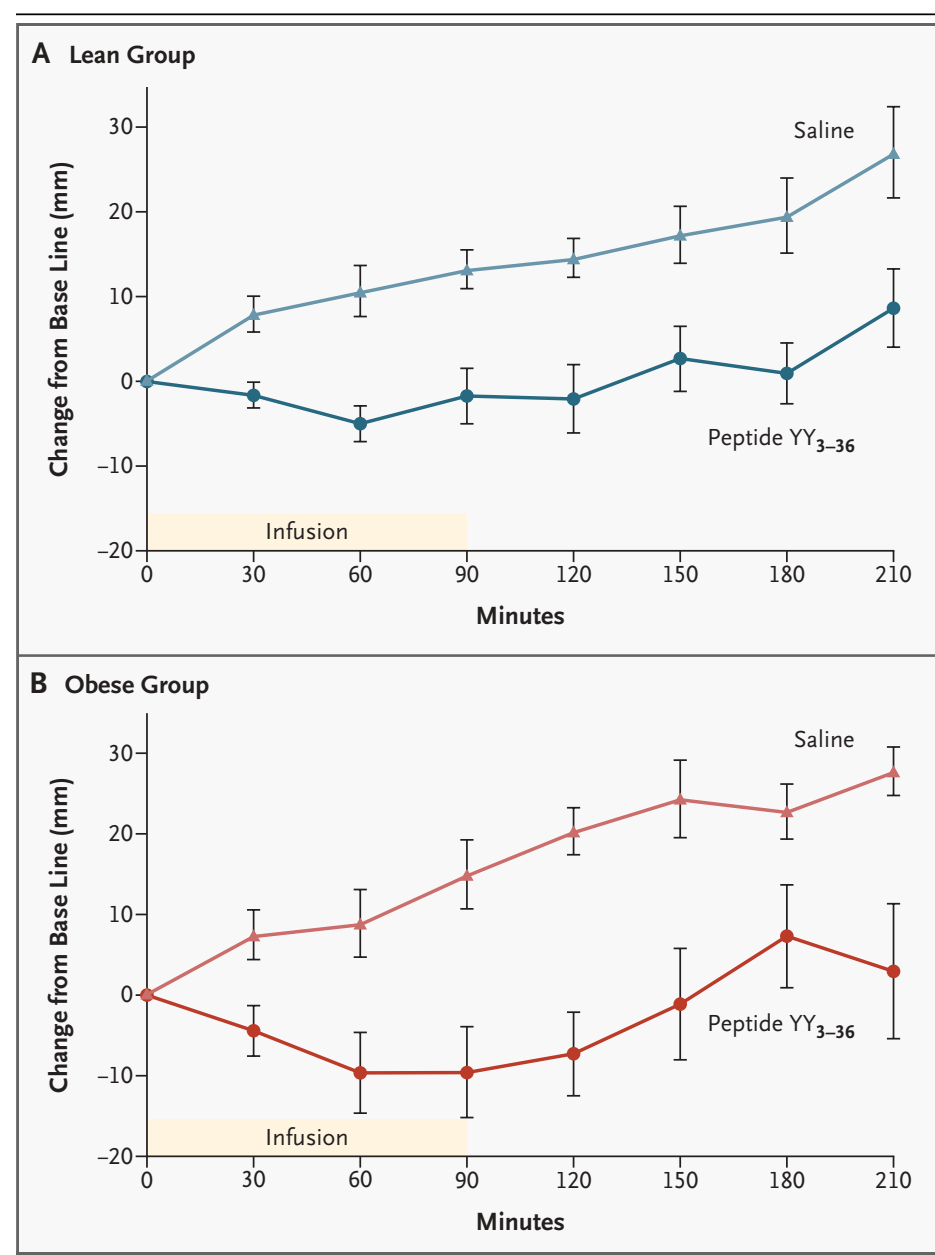

Figure 2. Appetite Scores for the Lean Subjects (Panel A) and the Obese Subjects (Panel B).

The scores are based on visual-analogue scales for perceived hunger during and after infusions, with negative values indicating less appetite. Scores were estimated every 30 minutes. The results are presented as the mean $( \pm S E)$ change from base-line scores for all 12 subjects.

fasting period on the day the subjects received saline (from $207.7 \pm 12.6$ pmol per liter at the beginning of the infusion to $247.4 \pm 13.8$ pmol per liter 210 minutes later) and then fell postprandially to $170.2 \pm 13.2$ pmol per liter 30 minutes after the meal began (Fig. 5). PYY infusion significantly decreased ghrelin levels during the fasting period and abolished the preprandial rise: the area under the curve for ghrelin from the beginning of the infusion to 210 minutes later was $13,510.6 \pm 813.5$ pmol per hour per liter on the day they received saline and $11,272.0 \pm 724.3$ pmol per hour per liter on the day they received PYY $(\mathrm{P}=0.001)$.

The ghrelin levels were markedly lower in obese 


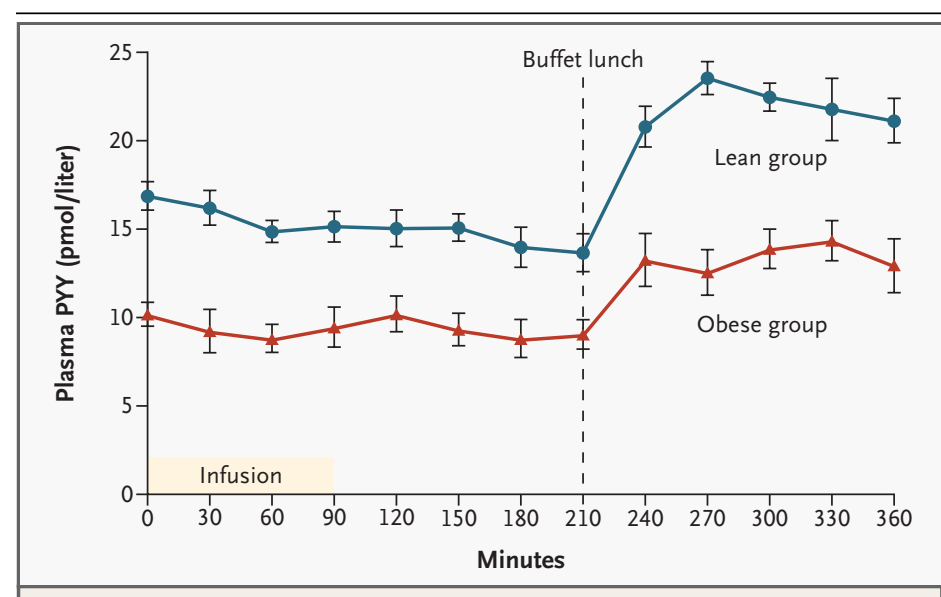

Figure 3. Mean ( \pm SE) Plasma Peptide YY (PYY) Levels in 12 Obese and 12 Lean Subjects during and after Infusion of Saline.

A buffet lunch was provided at the time indicated.
1.4 and $15.6 \pm 1.8$ pmol per liter, respectively) and were unaffected by PYY infusion.

\section{I SCUSSION}

We have previously found that PYY is released from the gut in proportion to the calories ingested ${ }^{15}$ and signals food intake to the appetite-regulating circuits of the brain. ${ }^{4}$ Furthermore, PYY infusion reduces food intake in subjects of normal weight, and repeated administration to rodents reduces weight gain. ${ }^{4}$ These findings suggest that PYY may be a useful treatment for obesity. PYY acts on the same hypothalamic neural circuits as leptin to regulate food intake. ${ }^{16,17}$ However, obesity is associated with resistance to the action of leptin, which greatly limits its therapeutic effectiveness in this condition. ${ }^{5,6} \mathrm{We}$ therefore studied whether obese subjects responded to the anorectic effects of PYY.

Infusion of PYY caused an equivalent inhibition subjects and, in contrast to the lean subjects, they had no significant preprandial rise in ghrelin levels during the infusion of saline: the ghrelin level was $87.7 \pm 14.1 \mathrm{pmol}$ per liter at the beginning of the infusion and 108.4 $\pm 18.7 \mathrm{pmol}$ per liter 210 minutes later. However, as in the lean subjects, the ghrelin levels decreased postprandially to $78.2 \pm 12.6 \mathrm{pmol}$ per liter 30 minutes after the start of the meal, and PYY infusion reduced the fasting ghrelin levels. The area under the curve for ghrelin in the obese subjects from the beginning of the infusion to 210 minutes later was $5973.2 \pm 1051.4$ pmol per hour per liter on the day they received saline and 4418.5 \pm 743.0 pmol per hour per liter on the day they received PYY $(\mathrm{P}=0.02)$.

PLASMA LEVELS OF LEPTIN, INSULIN, PANCREATIC PEPTIDE, AND GLP-I

The fasting plasma leptin levels were significantly higher in the obese group $(1.98 \pm 0.3$ and $0.5 \pm 0.1$ nmol per liter for obese and lean women, respectively; $0.71 \pm 0.2$ and $0.2 \pm 0.1 \mathrm{nmol}$ per liter for obese and lean men, respectively) and were unaffected by PYY infusion. Likewise, the fasting insulin levels were higher in obese subjects $(61.3 \pm 8.5 \mathrm{pmol}$ per liter in the obese group and $19.2 \pm 4.3 \mathrm{pmol}$ per liter in the lean group), and there was no effect of PYY infusion. The fasting plasma levels of GLP-1 were similar in obese and lean subjects $(14.0 \pm 1.1$ and $13.9 \pm 1.4$ pmol per liter, respectively) and were not affected by PYY infusion. The fasting levels of pancreatic peptide were similar in obese and lean subjects (14.4 \pm of appetite and food intake in the obese and lean groups, resulting in reduced cumulative 24-hour food intake. These findings indicate that obesity is not associated with substantial resistance to PYY. We found that fasting PYY levels were lower in the obese group than in the lean group and that there was a negative correlation between fasting PYY levels and body-mass index. Furthermore, postprandial PYY release was lower in obese than in lean subjects, despite the fact that the obese subjects consumed more calories at the buffet lunch. These findings are consistent with the hypothesis that a deficiency in circulating PYY may be involved in the pathogenesis of obesity. It is unclear whether low PYY levels initiate the development of obesity or whether PYY levels are reduced as a result of obesity. PYY appears to be a major factor limiting appetite after meals. ${ }^{17,18}$ If obesity is the cause of low levels of circulating PYY, impaired postprandial satiety signaling would result, leading to increased appetite and food intake, which would act to perpetuate the condition.

PYY is synthesized and released from specialized endocrine cells ( $\mathrm{L}$ cells) that are found primarily in the distal gastrointestinal tract. In response to the ingestion of nutrients, plasma PYY levels increase within 15 minutes, peak at around 60 minutes, and remain elevated for up to 6 hours. ${ }^{15}$ The initial increase occurs before nutrients have reached the L cells, implicating a neural or endocrine mechanism. The sustained release is thought to be due to the direct effects of the intraluminal gut contents 


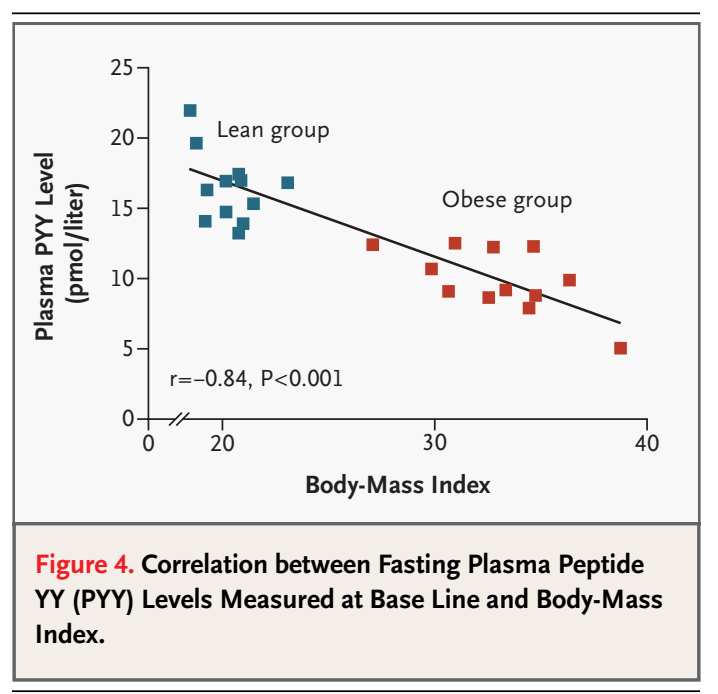

on the L cells. ${ }^{19}$ The reduced PYY levels in obesity may result from abnormalities in its synthesis, release, or clearance. Increased clearance is unlikely to have a major role, since after exogenous administration the rate of elimination was similar in the lean and the obese groups. However, the precise factors controlling PYY synthesis and release and the effect of obesity on these remain to be determined.

Our current studies give further insights into the potential mechanisms by which PYY inhibits food intake. Plasma levels of the gut hormone ghrelin rise preprandially, ${ }^{20}$ and administration of ghrelin increases food intake in rodents and humans. ${ }^{21-23}$ These findings suggest that ghrelin has a role in the regulation of meal initiation. ${ }^{20}$ In our current study of both lean and obese subjects, PYY infusion significantly decreases plasma ghrelin levels. This suppression may add to the effects of PYY on appetite reduction.

Currently, surgery is the only effective treatment for morbid obesity (body-mass index, $>40$ ). ${ }^{3,24} \mathrm{Re}$ cently, gastric-bypass surgery has been shown to be associated with low ghrelin levels, which may be re-

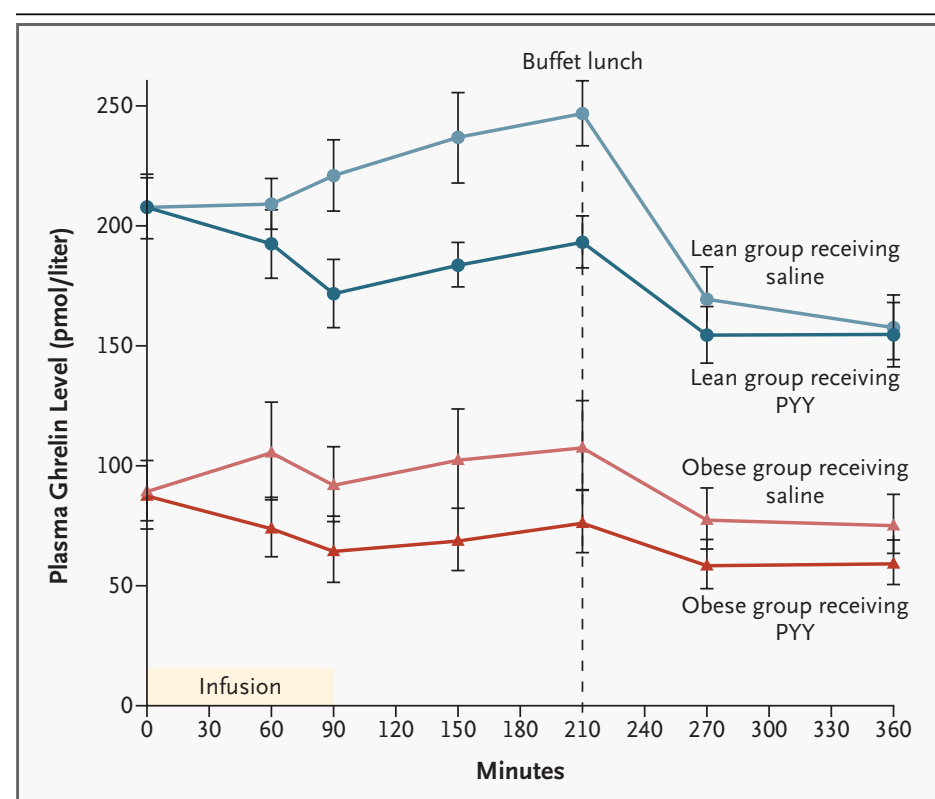

Figure 5. Mean ( \pm SE) Plasma Ghrelin Levels in 12 Obese and 12 Lean Subjects during and after Infusion of Saline or Peptide YY $_{3-36}$ (PYY).

A buffet lunch was provided at the time indicated.

sponsible for the reduced appetite associated with this procedure. ${ }^{25}$ Interestingly, PYY levels have been shown to be elevated in patients after jejunoilealbypass surgery, suggesting that increased PYY levels may also contribute to the reduced appetite and food intake observed in these patients. ${ }^{26}$

In summary, we have demonstrated that PYY levels are low in obesity, suggesting that PYY may be involved in the pathogenesis of this condition. Furthermore, the administration of PYY reduces appetite and food intake in normal and obese subjects. Thus, the administration of exogenous PYY or stimulation of the release of endogenous PYY may be an attractive therapeutic option for obesity.

Supported in part by the Wellcome Trust and by a grant (G7811974) from the Medical Research Council.

We are indebted to the volunteers who participated in the study.
REFERENCES

1. Peeters A, Barendregt J, Willekens F, Mackenbach JP, Al Mamun A, Bonneux L. Obesity in adulthood and its consequences for life expectancy: a life-table analysis. Ann Intern Med 2003;138:24-32.

2. Blackburn G. Effect of degree of weight loss on health benefits. Obes Res 1995;3: Suppl 2:211s-216s.

3. Trostler N, Mann A, Zilberbush N, Avinoach E, Charuzi II. Weight loss and food intake 18 months following vertical banded gastroplasty or gastric bypass for severe obesity. Obes Surg 1995;5:39-51.

4. Batterham RL, Cowley MA, Small CJ, et al. Gut hormone PYY(3-36) physiologically inhibits food intake. Nature 2002;418:650-4. 5. Chicurel M. Whatever happened to leptin? Nature 2000;404:538-40. Seeley RJ Baskin, tem control of food intake. Nature 2000; 404:661-71.

7. Van Strien T, Rookus MA, Bergers GP, Frijters JE, Defares PB. Life events, emotional eating and change in body mass index. Int J Obes 1986;10:29-35.

8. Garner DM, Garfinkel PE. The Eating Attitudes Test: an index of the symptoms of anorexia nervosa. Psychol Med 1979;9:2739. 
9. Raben A, Tagliabue A, Astrup A. The reproducibility of subjective appetite scores. Br J Nutr 1995;73:517-30. [Erratum, Br J Nutr 1995;74:283.]

10. Savage AP, Adrian TE, Carolan G, Chatterjee VK, Bloom SR. Effects of peptide YY (PYY) on mouth to caecum intestinal transit time and on the rate of gastric emptying in healthy volunteers. Gut 1987;28:166-70.

11. Adrian TE, Savage AP, Fuessl HS, Wolfe K, Besterman HS, Bloom SR. Release of peptide YY (PYY) after resection of small bowel, colon, or pancreas in man. Surgery 1987;101:715-9.

12. Fuessl HS, Adrian TE, Uttenthal LO, Bloom SR. Peptide YY in diabetics treated chronically with an intestinal glucosidase inhibitor. Klin Wochenschr 1988;66:985-9.

13. Adrian TE, Bloom SR, Bryant MG, Polak JM, Heitz PH, Barnes AJ. Distribution and release of human pancreatic polypeptide. Gut 1976;17:940-4.

14. Kreymann B, Williams G, Ghatei MA, Bloom SR. Glucagon-like peptide-1 7-36: a physiological incretin in man. Lancet 1987 2:1300-4.

15. Adrian TE, Ferri GL, Bacarese-Hamilton AJ, Fuessl HS, Polak JM, Bloom SR. Human distribution and release of a putative new gut hormone, peptide YY. Gastroenterology 1985;89:1070-7.

16. Cowley MA, Smart JL, Rubinstein M, et al. Leptin activates anorexigenic POMC neurons through a neural network in the arcuate nucleus. Nature 2001;411:480-4.

17. Schwartz MW, Morton GJ. Obesity: keeping hunger at bay. Nature 2002;418:595-7.

18. Saper CB, Chou TC, Elmquist JK. The need to feed: homeostatic and hedonic control of eating. Neuron 2002;36:199-211.

19. Imamura $M$. Effects of surgical manipu lation of the intestine on peptide $\mathrm{YY}$ and its physiology. Peptides 2002;23:403-7.

20. Cummings DE, Purnell JQ, Frayo RS, Schmidova K, Wisse BE, Weigle DS A preprandial rise in plasma ghrelin level suggests a role in meal initiation in humans. Diabetes 2001;50:1714-9.
21. Wren AM, Small CJ, Abbott CR, et al Ghrelin causes hyperphagia and obesity in rats. Diabetes 2001;50:2540-7.

22. Wren AM, Seal LJ, Cohen MA, et al. Ghrelin enhances appetite and increases food intake in humans. J Clin Endocrinol Metab 2001;86:5992.

23. Tschop M, Smiley DL, Heiman ML. Ghrelin induces adiposity in rodents. Nature 2000;407:908-13.

24. Mun EC, Blackburn GL, Matthews JB. Current status of medical and surgical therapy for obesity. Gastroenterology 2001;120: 669-81.

25. Cummings DE, Weigle DS, Frayo RS, et al. Plasma ghrelin levels after diet-induced weight loss or gastric bypass surgery. $\mathrm{N}$ Engl J Med 2002;346:1623-30.

26. Naslund E, Gryback P, Hellstrom PM, et al. Gastrointestinal hormones and gastric emptying 20 years after jejunoileal bypass for massive obesity. Int J Obes Relat Metab Disord 1997;21:387-92.

Copyright (c) 2003 Massachusetts Medical Society.

FULL TEXT OF ALL JOURNAL ARTICLES ON THE WORLD WIDE WEB

Access to the complete text of the Journal on the Internet is free to all subscribers. To use this Web site, subscribers should go to the Journal's home page (www.nejm.org) and register by entering their names and subscriber numbers as they appear on their mailing labels. After this one-time registration, subscribers can use their passwords to log on for electronic access to the entire Journal from any computer that is connected to the Internet. Features include a library of all issues since January 1993 and abstracts since January 1975, a full-text search capacity, and a personal archive for saving articles and search results of interest. All articles can be printed in a format that is virtually identical to that of the typeset pages. Beginning six months after publication, the full text of all Original Articles and Special Articles is available free to nonsubscribers who have completed a brief registration. 